\title{
Waarom burgers coproducent willen zijn
}

\author{
Een theoretisch model om de motivaties van coproducerende \\ burgers te verklaren ${ }^{*}$
}

Carola van Eijk \& Trui Steen

Coproductie is een vorm van publieke dienstverlening waarbij burgers en professionals samenwerken bij het managen en leveren van diensten en samen zorgen voor kwaliteitsborging. De overheid biedt verschillende mogelijkheden voor burgers om als coproducent op te treden, maar niet iedere burger besluit ook daadwerkelijk mee te doen. Hoewel er een groeiende belangstelling bestaat voor coproductie, zijn de inzichten in de motivaties van coproducerende burgers beperkt. Dit artikel richt zich op het individuele niveau om de motivatie van burgers te verklaren en maakt hierbij gebruik van inzichten uit verschillende literatuurstromingen. Het model wordt getoetst aan de hand van een casus over Nederlandse buurtpreventieteams. ${ }^{1}$

\section{Inleiding}

De afgelopen decennia veranderden ideeën over de rol van de burger in de samenleving. Van burgers wordt steeds meer verwacht dat zij niet alleen een beroep doen op hun rechten, maar ook de verantwoordelijkheden opnemen die 'het burger zijn' met zich meebrengt. In de wetenschap wordt daarbij verwezen naar het concept 'actief burgerschap' (vgl. Van Eijk \& Steen, 2012). Gemeenschapszin - de bereidheid 'iets' voor anderen en de samenleving als geheel te doen - vormt een belangrijk onderdeel hiervan (Hermes, 2009). Ook de ideeën over de rol van de overheid, en meer specifiek de relatie tussen overheid en samenleving, zijn veranderd. New Public Management, de Neo-Weberian State en New Public Governance benadrukken allemaal het belang van empowerment van burgers (Pollitt \& Bouckaert, 2011).

Toenemende druk op de overheidsfinanciën, vergrijzing en de roep van burgers om meer en betere diensten tegen zo laag mogelijke kosten hebben geleid tot een zoektocht naar andere vormen van publieke dienstverlening. Eén van de alternatieven is coproductie. De ervaringen zijn echter wisselend. Vaak blijkt het lastig om voldoende burgers te vinden die willen deelnemen. Deze tendens is overigens ook zichtbaar bij andere vormen van actief burgerschap. De WRR (2012, p. 5) noemt het 'zorgelijk dat slechts een kleine groep burgers zich voelt aangesproken door de pogingen van beleidsmakers hen te betrekken bij de samenleving'. Het blijkt essentieel burgers te mobiliseren door een sterke, motiverende en wervende

* De auteurs bedanken Wouter Steegh voor zijn bijdrage aan de dataverzameling.

1 Dit onderzoek is mede gefinancierd door Aspasia-NWO (Nederlandse Organisatie voor Wetenschappelijk Onderzoek). 
terminologie (Van Zuydam, Van de Velde \& Kuiper, 2013, p. 20). De overheid moet de institutionele kaders scheppen en ook zorgen dat burgers niet onverschillig toekijken. Inzicht in individuele kenmerken van burgers die al wel hebben besloten actief deel te nemen, kan helpen bij het vinden van de juiste terminologie om ook hen die nu nog aan de zijlijn staan te mobiliseren. Dat brengt ons bij de vraag: wat motiveert burgers om deel te nemen aan coproductieprocessen?

Hoewel in de coproductieliteratuur relevante eerste aanzetten gegeven zijn (vgl. Pestoff, 2012; Alford, 2009), zijn de theoretische en empirische inzichten in de motivaties van individuele burgers om deel te nemen aan coproductie beperkt. Dit is enigszins paradoxaal, omdat coproductie ook binnen de wetenschap onder toenemende belangstelling staat. Het concept 'coproductie' is hierbij een paraplubegrip dat veelvuldig wordt gebruikt en naar verschillende activiteiten verwijst. De bijdrage die burgers kunnen leveren en de fase waarin dit gebeurt, kan sterk verschillen (Bovaird \& Löffler, 2012). In deze studie nemen we de klassieke definitie als uitgangspunt: coproductie is een manier om publieke diensten te leveren waarbij professionals en burgers samen bijdragen aan kwaliteitsverhoging (Parks et al., 1981; Brandsen, Pestoff \& Verschuere, 2012).

Om een antwoord te vinden op de vraag wat burgers motiveert om deel te nemen aan coproductieprocessen, bouwen we een theoretisch model. In tegenstelling tot de meeste studies in de coproductieliteratuur gaan we daarbij niet uit van het inter-organisatie- (vgl. Dekker, Torenvlied, Lelieveldt \& Völker, 2010) of organisatieniveau (Alford, 2009). In plaats daarvan beargumenteren we dat individuele kenmerken van burgers van invloed zijn op hun deelname in coproductieprocessen. In andere literatuurstromingen, zoals over politieke participatie, vrijwilligerswerk en de motivaties van ambtenaren om zich in te zetten voor de publieke dienst, bestaan inzichten over motivaties op het individuele niveau. In dit artikel integreren we deze inzichten tot één model dat een verklaring biedt voor burgers om zich in te zetten voor coproductieprocessen. Vervolgens bespreken we een casus over buurtpreventieteams.

\section{Naar een theoretisch model}

Bij het zoeken naar een verklaring voor de betrokkenheid van burgers beperken we ons niet enkel tot de coproductieliteratuur, maar verruimen we onze blik naar andere concepten en theorieën die interessante inzichten kunnen bieden. Vrijwilligerswerk betreft, net als coproductie, vrijwillig engagement van burgers die zich willen inzetten voor de maatschappij zonder dat daar een loon tegenover staat. De literatuur over politieke participatie kan relevante inzichten geven, omdat het zowel bij politieke participatie als coproductie gaat om engagement voor de samenleving en deelname aan een overheidsproces met het doel de uitkomsten van dat proces te beïnvloeden. Ook met het concept Public Service Motivation (PSM) bestaan overeenkomsten: beide gaan over een gerichtheid op het algemeen belang. Bovendien wordt PSM reeds toegepast om actief burgerschap te verklaren. Bij het integreren van deze literatuurstromingen komen drie factoren naar 


\section{Figuur 1 Deelname van individuele burgers aan coproductieprocessen} verklaard

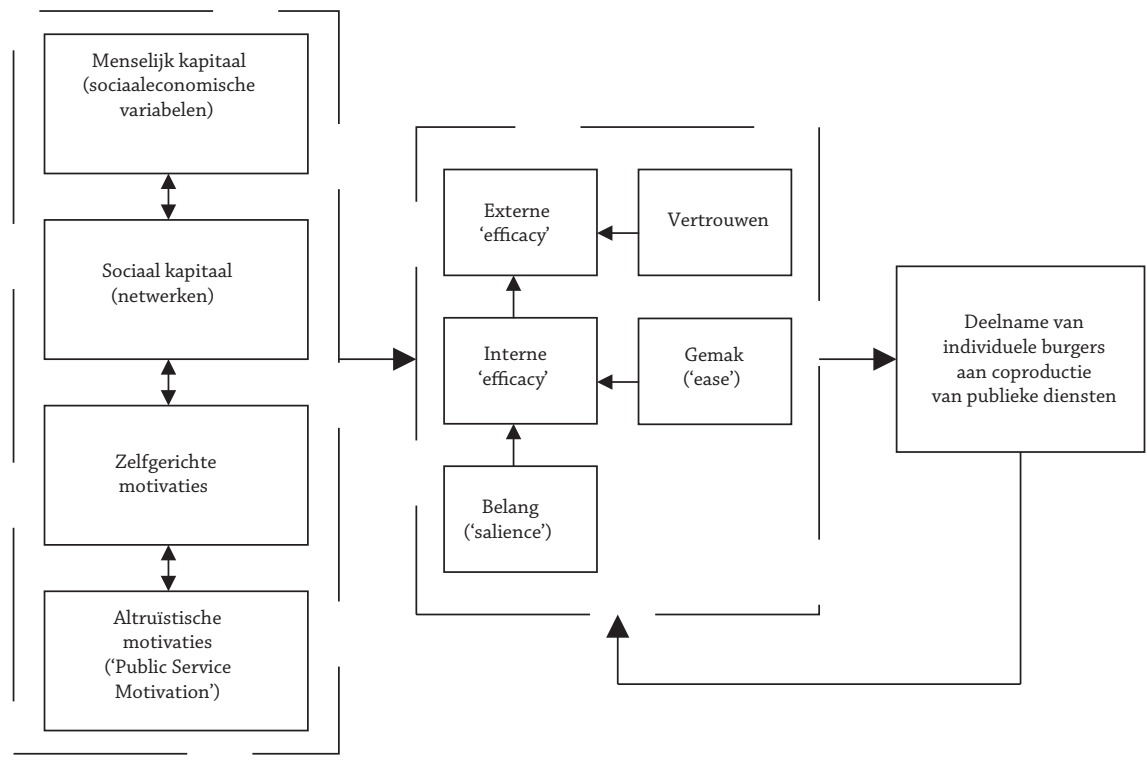

voren. Achtereenvolgens bespreken we de percepties van burgers over zowel de taken als hun competenties om een bijdrage te leveren aan publieke dienstverlening, de sociaaleconomische en sociale capaciteiten, en zelfgerichte en altruïstische motivaties. Figuur 1 integreert deze factoren in één model. Hierbij wordt opgemerkt dat het mengen van deze stromingen tot één model een uitdaging is. Gezien de verschillende, maar tegelijk aan elkaar linkende verklaringen biedt het echter wel een meerwaarde voor het huidige coproductieonderzoek. Gezien de omvang van dit artikel kunnen de concepten slechts in beperkte zin worden uitgewerkt; dit artikel hoopt verdere (theoretische) discussies aan te wakkeren.

\section{Percepties}

Voor een burger is het onmogelijk om aandacht te schenken aan ieder onderwerp en alle mogelijkheden voor actieve betrokkenheid te overwegen. Betrokkenheid valt vaak samen met een specifiek probleem waar, bijvoorbeeld door de media, de aandacht op wordt gericht (Verhoeven, 2009, pp. 60-68). Slechts als een burger het onderwerp relevant en belangrijk genoeg vindt en daardoor de benodigde investeringen (bijvoorbeeld in tijd) wil maken, zal besloten worden daadwerkelijk actief te worden. In de afweging zal ook de perceptie van het belang van de geproduceerde dienst worden meegenomen; bijvoorbeeld hoe de dienst het leven van de burger zelf of van vrienden of familie beïnvloedt (Pestoff, 2012, pp. 23-25). In de literatuur wordt hiervoor ook wel het begrip salience gebruikt. Dit is de eerste stap in een 'besluitenreeks', zoals weergegeven in het midden van figuur 1. 
De tweede stap betreft het overwegen van de eigen competenties: 'Kan ik een coproducent zijn?' Dit sluit aan bij het begrip internal efficacy, dat gebruikt wordt in de politicologie om bijvoorbeeld kiesgedrag te verklaren en dat aanduidt hoe competent een burger zichzelf vindt om het politieke proces te begrijpen en effectief daaraan deel te nemen (Craig, Niemi \& Silver, 1990, p. 290). Overeenkomstig zal een burger bij het afwegen van deelname aan coproductieprocessen zich afvragen of hij/zij competent genoeg is om het proces van publieke dienstverlening te begrijpen en te beïnvloeden. De afweging van interne efficacy zal beïnvloed worden door de ease van het desbetreffende coproductieproces: hoe meer investeringen een burger moet doen, hoe groter de kans dat hij/zij besluit niet mee te doen. Bepalende factoren zijn bijvoorbeeld de afstand tot de dienstverlener en de beschikbare informatie (Pestoff, 2012, pp. 23-25).

De derde stap betreft de external efficacy: de percepties over de verwachte impact die deelname zal hebben. In de politicologie verwijst het concept naar de verwachte responsiviteit van overheidsautoriteiten ten aanzien van de wensen van burgers (Craig et al., 1990, p. 290). Voor coproductie betreft het daarnaast ook de verwachting of de reguliere dienstverlener openstaat voor interactie. Het vertrouwen dat de burger heeft in de organisatie, zal hierop van invloed zijn: hoe meer vertrouwen in de organisatie, hoe groter de kans dat een burger deelname zinvol acht. Ook het vertrouwen dat de ambtenaar heeft in de burger, is een belangrijke verklarende factor als het gaat om de investeringen van burgers (Yang, 2005).

Tot slot wordt, zoals weergegeven in de feedbackloop in figuur 1, de afweging van salience en efficacy beïnvloed door ervaringen die eerder zijn opgedaan tijdens coproductieprocessen. De ervaringen die iemand heeft - bijvoorbeeld over hoe open de organisatie is of hoeveel vaardigheden nodig zijn om de taken uit te kunnen voeren - zullen bepalen of een coproducent in de toekomst bereid is opnieuw aan een coproductieproces deel te nemen.

\section{Capaciteiten}

In de politicologie wordt gewezen op de invloed van sociaaleconomische factoren op politieke participatie (Timpone, 1998). Ook bij vrijwilligerswerk zijn factoren als inkomen, opleiding en beroep van invloed (Dekker \& Halman, 2003). Wat betreft de invloed van geslacht lijkt er een verschil te bestaan tussen verschillende vormen van coproductie: waar vrouwen relatief vaker dan mannen betrokken zijn bij individuele vormen van coproductie, lijkt de invloed van geslacht weg te vallen als het gaat om collectieve coproductieprocessen (Bovaird, Van Ryzin, Löffler \& Parrado, 2012).

Daarnaast blijkt niet alleen wie je bent bepalend voor deelname aan coproductie, maar ook waar je vandaan komt (Thijssen \& Van Dooren, 2013). Het aantal initiatieven in de wijk bijvoorbeeld kan een verklaring bieden voor wie coproduceert. Hiermee lijkt het concept sociaal kapitaal relevant. Sociaal kapitaal kan (traditioneel) worden opgebouwd via deelname aan de kerk, lidmaatschap van een groep, huwelijkse status of een ander netwerk (Putnam, 1993). Ook deelname aan het politieke proces kan helpen 'een beter burger' te worden (Pateman, 1970). Zo is 
bij vrijwilligerswerk gevonden dat mensen die actief zijn in de samenleving (via werk of andere activiteiten) met meer mogelijkheden voor vrijwilligerswerk in aanraking komen en ook vaker hieraan deelnemen (vgl. Steen, 2006).

\section{Motivaties}

In literatuur over politieke participatie, vrijwilligerswerk en zelfgeorganiseerde collectieve acties wordt vaak verwezen naar altruïstische motivaties, zoals gemeenschapszin en het besef dat je als burger een verantwoordelijkheid hebt ten opzichte van de samenleving (Reed \& Selbee, 2003). Dit raakt de kern van het concept actief burgerschap. Altruïstische motivaties komen voort uit gevoelens van verbondenheid met de samenleving en identificatie met publieke doelen (Ostrom, 2009 in Alford, 2012).

De studie van Public Service Motivation biedt meer inzicht in altruïstische motivaties. Dit concept betreft gerichtheid van ambtenaren op het algemeen belang (Perry \& Hondeghem, 2008). Hoewel PSM oorspronkelijk werd gebruikt als verklaring waarom mensen voor de publieke sector als werkgever kiezen, is de huidige toepassing breder. Interessant is de link met organizational citizenship behavior, dat gezien kan worden als de organisationele equivalent van burgerlijke verantwoordelijkheden zoals beschreven in de politicologie (Graham, 1991). Ook buiten de werkvloer leidt een hogere PSM tot meer sociaal gedrag. Zo vergroot het bijvoorbeeld de kans op deelname aan vrijwilligerswerk (Coursey, Brudney, Littlepage \& Perry, 2011). Langs dezelfde weg kan een hogere verbondenheid met het algemeen belang bij burgers leiden tot meer bereidheid tot actieve inzet. Deelname aan coproductieprocessen komt dan voort uit de bereidheid iets voor de samenleving te doen.

Naast altruïstische motieven kunnen ook zelfgerichte motivaties een verklaring bieden voor deelname: de burger wil door zijn deelname diensten afnemen van een hogere kwaliteit tegen lagere kosten. Dit is een meer materialistische drijfveer, zoals onderscheiden door Sharp (1978 in Alford, 2002). Onder egoïstische motivaties vallen ook solidaire (het verbonden voelen met anderen) en expressieve (het hebben van een tevreden gevoel omdat je bijgedragen hebt aan een groter geheel) motivaties, evenals het vergroten van eigen competenties of, in meer negatieve zin, het voldoen aan wettelijke verplichtingen (zoals het betalen van belastingen) om sancties te voorkomen (Alford, 2002).

Tot slot is het belangrijk aan te geven hoe de drie factoren - percepties, capaciteiten en motivaties - samenhangen. Motivaties en capaciteiten beïnvloeden in interactie de percepties van een individu. Zo kan het netwerk waarin je opereert (sociaal kapitaal) een gerichtheid op het maatschappelijk belang stimuleren en zo bijdragen aan altruïstische motivaties. Capaciteiten en motivaties vormen samen de bril waarmee je naar de omgeving kijkt en bepalen of je een coproductieproces belangrijk vindt en hoe gemakkelijk je efficacy positief beoordeelt. Toch resulteert dit nog niet direct in gedrag (d.w.z. deelname aan coproductieprocessen). In de psychologische literatuur bestaat discussie over de relatie tussen attitude (houding) en gedrag (Bandura, 1997). Gesteld kan worden dat factoren als efficacy het 
gedrag van individuen bepalen, maar dat dit geïntermedieerd wordt door de houding. In andere woorden, de percepties bepalen hoe je staat tegenover coproductieprocessen (attitude) en dat bepaalt uiteindelijk of je daadwerkelijk meedoet of niet (gedrag).

\section{Een empirische verkenning: de casus buurtpreventieteams}

Om de toepasbaarheid van het model te verkennen is onderzocht wat burgers beweegt om deel te nemen aan buurtpreventieteams. Een buurtpreventieteam 'coproduceert' samen met professionals (gemeente en politie) een uitkomst, namelijk veiligheid en een leefbare wijk. De taken van de 'buurtpreventen', zoals de burgers uit het team worden genoemd, variëren van deelname aan telefooncirkels tot het actief patrouilleren in de wijk. De organisatie gebeurt op lokaal niveau en kan het initiatief zijn van zowel de gemeente als burgers. De rol van de gemeente verschuift naar een faciliterende: $\mathrm{zij}$ ondersteunt de burgers bij het vervullen van hun taken door middel van bijvoorbeeld scholing (Centrum Criminaliteitspreventie Veiligheid, 2010).

Om inzicht te krijgen in de persoonlijke motivaties zijn twee focusgroepen georganiseerd met in totaal tien respondenten. De respondenten zijn preventen die actief rondes lopen, een organisator van telefooncirkels, een voorzitter van een buurtpreventieteam en een politieagent. Zij werden uitgenodigd om in een relaxte setting te praten over hun deelname aan het buurtpreventieteam en hun motivaties, zonder dat ze specifieke vragen kregen voorgelegd. Dit leidde tot een discussie die zo dicht mogelijk staat bij de percepties en beleveniswereld van de burgers zelf. Het theoretisch model vormde vervolgens de leidraad om structuur te geven aan de gevonden antwoorden.

\section{De motivatie van buurtpreventen}

De percepties over taken en verantwoordelijkheden lopen uiteen. Terwijl sommigen van mening zijn dat zij enkel ondersteunend zijn, zien anderen zichzelf als de 'ogen en oren van de politie'. Dit werkt door in de impact die burgers denken te hebben met hun deelname. Eén van de respondenten vertelt: 'Wij kunnen niks meer dan elke burger kan, alleen bij calamiteiten kunnen wij contact opnemen met de politie.' Hiertegenover staat een respondent die 'het idee had dat hij echt nodig zou zijn'. Het buurtpreventieteam wordt gezien als een instrument om te zorgen voor sociale cohesie. Je bent niet alleen buurtprevent voor jezelf, maar helpt een 'gemeenschappelijk belang mee te verdedigen' en 'wordt er echt weer een dorp van met elkaar'.

Hoewel 'beroep of achtergrond helemaal niet uitmaken', benadrukken de respondenten wel het belang van vaardigheden. Mensenkennis en communicatieve vaardigheden zijn belangrijk, bijvoorbeeld om contact te kunnen leggen met hangjongeren. 'Als de jeugd lastig is, dan wil je ze toch een beetje bewust maken van wat 
ze aan overlast veroorzaken.' Buurtpreventen proberen het gesprek aan te gaan en de verhalen achter de jongeren te horen. Dit werken met jongeren is voor sommigen een belangrijke drijfveer. 'De jongeren vinden het ook leuk dat ze die verhalen kwijt kunnen.'

Andere respondenten benadrukken de gezelligheid en het contact met andere buurtpreventen: 'De hoofdgedachte waarom ik lid van de buurtpreventie ben, is omdat ik wil werken in groepsverband.' Ook de contacten met andere buurtbewoners wordt gewaardeerd. 'Vooral de oudere mensen vinden het fijn als ze je zien lopen' en 'door de buurtpreventie weet je wat er speelt'. Opvallend is dat sommige respondenten hierbij wijzen op gevoelens van waardering. Ze vertellen niet alleen dat ze herkend worden op straat, maar ook dat ze gewaardeerd worden voor wat ze doen. Zij lijken meer zelfvertrouwen te krijgen door hun rol als coproducent. De speciale kleding die ze dragen tijdens patrouilles, draagt hier wellicht ook aan bij: het geeft het gevoel iets belangrijks te doen.

Vaak organiseert de gemeente cursussen voor de buurtpreventieteams. Eén respondent geeft aan dit maar niets te vinden: 'Ik doe het toch vrijwillig?!' De meeste respondenten vinden dit echter heel belangrijk en zien het soms zelfs als een reden om mee te doen. Van de trainingen leer je veel en je kunt jezelf erdoor ontwikkelen.

Een aantal respondenten is lid geworden vanwege problemen in de wijk. Ze willen dat hun kinderen veilig kunnen opgroeien en later zonder problemen kunnen gaan stappen. Ook een inbraak in de omgeving kan een directe aanleiding vormen. Een aantal respondenten combineert deze gevoelens van onveiligheid met ontevredenheid over de politie: 'Ik doe mee uit onvrede, omdat de politie eigenlijk niet meer op tijd ter plaatse kan zijn.' Anderen delen dit gevoel, maar tonen meer begrip: 'We merken dat de politie aan alle kanten mensen tekort komt en daar geen geld voor heeft, en op deze manier kan je dan toch ter wille zijn.' De politie kan het niet alleen en als burger heb je dan niet alleen rechten, maar ook een verantwoordelijkheid naar je eigen leefomgeving toe.

De leefbaarheid in de omgeving kan worden vergroot door een goede samenwerking tussen buurtpreventieteam, gemeente en politie. Vooral tussen politie en buurtpreventieteam bestaat een afhankelijkheidsrelatie; voor het delen van informatie en het hebben van een back-up als een buurtprevent zich bedreigd voelt. Vertrouwen en samenwerking worden vaak genoemd. De ervaringen zijn hierbij wisselend. Sommige respondenten voelen zich gewaardeerd door de gemeente en politie, terwijl anderen aangeven dat de relatie verbeterd kan worden. 'Een beetje professionele terugkoppeling, van wat gaan jullie met die gegevens doen, daar zou ik wel eens wat meer van willen zien.' Toch zien ook deze respondenten het belang van hun inzet. Het gevoel wordt breed gedragen dat zij iets kunnen betekenen. 'Die uurtjes die je dan inderdaad loopt, die zijn wel superbelangrijk en maken wel net even een verschil voor de leefomgeving.' Zoals een van hen zegt: 'Als er te weinig incidenten zijn, waarom zou ik dan nog lopen?' 


\section{Conclusie}

In dit artikel hebben we verschillende literatuurstromingen geïntegreerd in een model om de deelname van burgers aan coproductieprocessen te verklaren. Door coproductieliteratuur aan te vullen met theorieën op het gebied van politieke participatie, vrijwilligerswerk en PSM kunnen drie factoren onderscheiden worden: percepties, capaciteiten en motivaties. De casus laat zien dat buurtpreventen het belang van vaardigheden onderstrepen. Dit wijst op een overweging van interne efficacy. Waar deze vaardigheden ontwikkeld worden (een netwerk of beroep), geven de respondenten niet aan. De meeste buurtpreventen die deelnamen aan het onderzoek, vonden de cursussen die ze krijgen vanuit de gemeente, erg belangrijk: door deelname aan het buurtpreventieteam kun je jezelf ontwikkelen. Ook sociale contacten opdoen is belangrijk. Dit duidt op verschillende zelfgerichte motieven. Maar ook altruïstische motieven die linken met PSM komen aan bod: deelnemers willen iets voor de samenleving doen en hun eigen verantwoordelijkheid nemen. Wat opvalt, is dat preventen hun deelname starten vanuit concrete problemen (salience), maar ook vanuit onvrede over de autoriteiten. Zij vertrouwen er niet meer op dat de politie dit alleen kan oplossen. Daarmee lijkt het niet, zoals op basis van de literatuur werd verwacht, te gaan om trust, maar ook om distrust.

Hoewel deze studie een eerste aanzet geeft om de toepasbaarheid van het model te verkennen, moet hierbij worden opgemerkt dat het een studie betreft van beperkte omvang. Focusgroepen zijn geschikt om inzicht te krijgen in de percepties en denkbeelden van respondenten, maar zijn niet representatief voor de gehele populatie. De uitkomsten kunnen dan ook niet gegeneraliseerd worden. Vervolgonderzoek, bijvoorbeeld met een survey, is daarom nodig om het model verder te toetsen. Daarbij zou ook informatie verzameld kunnen worden bij burgers die niet betrokken zijn bij coproductieprocessen, zodat het voor de overheid nog duidelijker wordt hoe mensen gericht kunnen worden aangesproken en gestimuleerd om zich te engageren als coproducent.

\section{Literatuur}

Alford, J. (2002). Why Do Public-Sector Clients Coproduce? Toward a Contingency Theory. Administration \& Society, 34(1), 32-56.

Alford, J. (2009). Engaging Public Sector Clients. From Service-Delivery to Co-production. Houndmills: Palgrave Macmillan.

Alford, J. (2012). The Multiple Facets of Co-production. Building on the work of Elinor Ostrom. Paper for the Seminar on 'Co-production: the State of the Art', 22-23 November 2012, Budapest.

Bandura, A. (1997). Self-Efficacy. The Exercise of Control. New York: W.H. Freeman.

Bovaird, T., \& Löffler, E. (2012). From Engagement to Co-Production. How Users and Communities Contribute to Public Services. In V. Pestoff, T. Brandsen \& B. Verschuere (Eds.), New Public Governance, the Third Sector and Co-Production (pp. 35-60). New York/London: Routledge. 
Bovaird, T., Ryzin, G. van, Löffler, E., \& Parrado, S. (2012). Influences on Collective Co-Production of Public Services: Which Citizens Most Participate in Complex Governance Mechanisms? Paper for the Seminar on 'Co-production: the State of the Art', 22-23 November 2012, Budapest.

Brandsen, T., Pestoff, V., \& Verschuere, B. (2012). Co-Production as a Maturing Concept. In V. Pestoff, T. Brandsen \& B. Verschuere (Eds.), New Public Governance, the Third Sector and Co-Production (pp. 1-9). New York/London: Routledge.

Centrum Criminaliteitspreventie Veiligheid. (2010). Buurtpreventie. Gepubliceerd 13 november 2010 op http://www.hetccv.nl/dossiers/wijkinterventies/buurtpreventie.

Coursey, D., Brudney, J.L., Littlepage, L., \& Perry, J.L. (2011). Does Public Service Motivation Matter in Volunteering Domain Choices? A Test of Functional Theory. Review of Public Personnel Administration, 31(1), 48-66.

Craig, S.C., Niemi, R.G., \& Silver, G.E. (1990). Political Efficacy and Trust: A Report on the NES Pilot Study Items. Political Behavior, 12(3), 289-314.

Dekker, K., Torenvlied, R., Lelieveldt, H., \& Völker, B. (2010). Coproductie. Samenwerking van de lokale overheid met maatschappelijke organisaties in de buurt. Den Haag: Nicis Institute.

Dekker, P., \& Halman, L. (2003). Volunteering and Values: An Introduction. In P. Dekker \& L. Halman (Eds.), The Values of Volunteering. Cross-Cultural Perspectives (pp. 1-17). New York: Kluwer Academic/Plenum Publishers.

Eijk, C.J.A. van, \& Steen, T.P.S. (2012). Motivated for active citizenship: Citizens' changing role in the provision of public services. Paper presented at the 40th ECPR Joint Sessions of Workshops, University of Antwerp.

Graham, J.W. (1991). An essay on organizational citizenship behavior. Employee Responsibilities and Rights Journal, 4(4), 249-270.

Hermes, J. (2009). To catch a thief... Burgerschap in het leven van alledag. Bestuurskunde, $1,68-72$.

Ostrom, E. (2009). Beyond Markets and States. Polycentric Governance of Complex Economic Systems. Nobel Prize Lecture, Oslo.

Parks, R.B., Baker, P.C., Kiser, L., Oakerson, R., Ostrom, E., Ostrom, V., Percy, S.L., Vandivort, M.B., Whitaker, G.P., \& Wilson, R. (1981). Consumers as co-producers of public services. Some institutional and economic considerations. Policy Studies Journal, 9(7), 1001-1011.

Pateman, C. (1970). Participation and democratic theory. Cambridge: Cambridge University Press.

Perry, J.L., \& Hondeghem, A. (Eds.). (2008). Motivation in public management. The call of public service. Oxford: Oxford University Press.

Pestoff, V. (2012). Co-Production and Third Sector Social Services in Europe. In V. Pestoff, T. Brandsen \& B. Verschuere (Eds.), New Public Governance, the Third Sector and Co-Production (pp. 13-34). New York/London: Routledge.

Pollitt, C., \& Bouckaert, G. (2011). Public Management Reform. A comparative analysis: NPM, Governance and the Neo-Weberian State. Oxford: Oxford University Press.

Putnam, R.D. (1993). Making Democracy Work. Civic traditions in modern Italy. Princeton: Princeton University Press.

Reed, P., \& Selbee, L.K. (2003). Do People Who Volunteer Have a Distinctive Ethos? A Canadian Study. In: P. Dekker \& L. Halman (Eds.), The Values of Volunteering. CrossCultural Perspectives (pp. 91-109). New York: Kluwer Academic/Plenum Publishers. 
Sharp, E. (1978). Citizen organizations and participation in law enforcement advocacy and coproduction: The role of incentives. Unpublished doctoral dissertation, University of North Carolina at Chapel Hill.

Steen, T. (2006). Public Sector Motivation: Is There Something to Learn From the Study of Volunteerism? Public Policy and Administration, 21(1), 49-62.

Thijssen, P., \& Dooren, W. van (2013). The Context of Coproduction. Does neighbourhood matter? Paper for the IIAS Study Group on Co-production of Public Services, TPC Conference, The Hague.

Timpone, R.J. (1998). Structure, Behavior, and Voter Turnout in the United States. The American Political Science Review, 92(1), 145-158.

Verhoeven, I. (2009). Burgers tegen beleid. Een analyse van dynamiek in politieke betrokkenheid. Amsterdam: Aksant.

WRR (2012). Vertrouwen in burgers. Den Haag/Amsterdam: WRR/Amsterdam University Press.

Yang, K. (2005). Public Administrators' Trust in Citizens: A Missing Link in Citizen Involvement Efforts. Public Administration Review, 65(3), 262-275.

Zuydam, S. van, Velde, B. van de, \& Kuiper, M. (2013). Het maatschappelijk middenveld in beweging. Een internationale vergelijking van dynamiek in herkomst, perspectief en invulling van vermaatschappelijking. Bestuurskunde, 22(1), 13-22. 